\title{
A Contrastive Analysis of the Links of Textuality in Abstracts Written by Persian and English Writers in Clinical Psychology Journals
}

\author{
Abbas Mehrabi Boshrabadi (Corresponding author) \\ English Department, Islamic Azad University, Khorasgan (Isfahan) Branch, \\ PO box 81595-158, Isfahan, Iran \\ E-mail: abbas.mehrabi596@gmail.com \\ Reza Biria \\ English Department, Islamic Azad University, Khorasgan (Isfahan) Branch, \\ PO box 81595-158, Isfahan, Iran \\ E-mail: r_biria@yahoo.com \\ Maryam Hodaeian \\ English Department, Sobh-e Sadegh Institute of Higher Education, \\ PO box 43654, Isfahan, Iran \\ E-mail: maryamhadaiyan@yahoo.com
}

Received: 02-02-2014

doi:10.7575/aiac.ijalel.v.3n.4p.136
Accepted: 20-03-2014

Published: 01-07-2014

\begin{abstract}
It is generally agreed today that lexical cohesion is one of the fundamental elements of the text texture achieved through lexical semantic relations dominating the arrangement of propositional units in a text. Accordingly, this study sought to compare and contrast the textual links or lexical cohesive devices enlisted in the psychological abstracts written by Persian and English writers. To this end, 40 abstracts from Persian and English articles, 20 in each language, published in clinical psychology journals were randomly selected. The framework serving as tertium comprationis for analyzing lexical cohesion markers was derived from Halliday and Hasan's (1976) model [Halliday, M. A. K., \& Hasan, R. (1976). Cohesion in English. London: Longman]. A frequency count analysis was employed to gauge the number of occurrences of cohesive links in the selected corpus. The results revealed that lexical links of synonymy and repetition were more frequent than other cohesive devices in both English and Persian abstracts.
\end{abstract}

Keywords: Links of textuality, Lexical cohesive devices, Synonymy, Repetition, Clinical psychology journal abstracts

\section{Introduction}

\subsection{Cohesion and Coherence in Contrast}

"Cohesion" and "coherence" in a written text are two semantically different but interrelated concepts. Clearly, text coherence means that the message conveyed by the writer is understandable as a unified whole-that is, the reader can make sense out of the overall meaning of the text. The problem here is that the definition of the term coherence is not that easy and different practitioners of the field have defined the concept differently (see Hoey, 2005; Gutwinski, 2007, for further information). For instance, coherence is said to be one of the main properties of the semantic structure of discourse, which according to Van Dijk (1977), is "based on the interpretation of each individual sentence relative to the interpretation of other sentences" (P. 93). Many practitioners and researchers, however, contend that it is the responsibility of the reader to interpret and evaluate the text as a unified whole. In this regard, Fairclough (1995) notes that "[the] relations of coherence between clauses and sentences of a text are not objective properties of the text; they are relations that have to be established by people interpreting it." (P. 122)

On the other hand, cohesion in a text is developed when the writers use some clear signals and markers to link different parts of their text, be it different parts of a given sentence, different sentences of a given paragraph, or different paragraphs of a given text. Once a text achieves its cohesion by logically connecting different parts of a text using related linguistic means or markers, its overall meaning may also be developed and interpreted by the reader. Accordingly, as De Beaugrande and Dressler (2004) maintain, cohesion is a relationship among different sentences or different parts of a given sentence, whereas coherence is a relationship between concepts and meanings derived from those sentences. Accordingly, it can be claimed that cohesion in a text is developed by the writer, while coherence is developed by the reader.

Halliday and Hasan (1976) provide a semantic description for the concept of cohesion emphasizing the relations of the meaning units existing within the text. They further argue that discourse cohesion results from the interpretation of the 
texture signaled by the elements that are organized intelligently throughout the text. Evidently, cohesive relations or links of textuality are the ways two or more items in a given text are semantically adjoined to materialize a specific rhetorical function. Such pairwise interrelated items are known as "ties". Consider the following example:

Wash and core six cooking apples. Put them into a fireproof dish.

It is evident that them in the second clause refers to the previous noun apples. This tie is called Anaphoric, which links two sentences of a given text together so that the reader can think of them as a whole. These textual links can be achieved through both grammatical and lexical markers, which will be explained in the coming section. As such, textual links or cohesive devices would play a significant role in achieving coherence.

\subsection{Classifications of Cohesive Devices}

As Tanskanen (2006) maintains, cohesion in a text can be determined through both the grammatical and lexical aspects of the text. Accordingly, Cohesion can be divided into two different but interrelated sub-types, i.e., grammatical and lexical cohesion. Grammatical cohesion refers to a combination of terms between sentences forming the grammatical features of the text. Halliday and Hasan (1976) classify grammatical cohesion into four categories; namely, References, Substitutions, Ellipses, and Conjunctions. References occur when one item in a given text points to another element for its interpretation. References are further divided into two sub-types: Endophora and Exophora. The next two categories of the grammatical cohesion, viz, Substitutions and Ellipses, are quite similar. In fact, substitutions are the result of replacement of one element with another, while ellipses result from the omission of an item or its replacement by nothing. Differently stated, ellipsis occurs when something that is structurally necessary is left unsaid because it has already been stated. In this regard, Halliday and Hasan point out that substitutions and ellipses belong to the same process and the latter actually involves a kind of substitution in which something is replaced by nothing. Finally, Conjunctions refer to a specification of the way in which what is to follow is systematically connected to what has been stated before. These connections can be achieved through such words as however, on the other hand, then, and so on.

Lexical cohesion, by contrast, deals with the meaning in a given text. It concerns the way in which lexical items relate to each other and to other cohesive devices so that textual continuity is created. Sources for lexical cohesion can be classified into different categories with different authors offering different classifications. For the purpose of the study, the following categorization, which is based on the Halliday and Hasan's (1976) model, is taken into consideration. According to their model, Halliday and Hasan divided the lexical cohesive markers into three fundamental categories; namely, Repetition, Synonymy, and Collocation. Repetition (R), establishing a cohesive tie between at least two identical lexical items, is the most obvious sub-type of lexical cohesive markers. To put it simply, repetition is a sort of lexical cohesive marker that repeats a constituent in a text. As an illustration, in the following short text:

Ali met a bear. The bear was bulgy. (bear/bear)

The word bear has been repeated twice. The next category, Synonymy (S), refers to the choice of a lexical item that is in a sense synonymous with a preceding one. In other words, synonymy occurs among words that are similar in meaning. Different types of synonymy can be classified as follow:

1) With identity of reference:

Example: I heard a sound, but I couldn't figure out where that noise came from. (sound/noise)

2) Without identity of reference

A) Hyponymy $(\mathrm{H})$ : Describes a "specific-general" relationship between lexical items. This type of synonymy involves a lexical cohesion sub-type that creates a relationship between constituents having a general meaning. The first is called a subordinate and the second denoting a specific meaning is labeled as hyponymy (e.g., sun/star).

B) Meronymy (M): Describes a "part-whole" relationship between lexical items. (e.g., planet/solar system).

C) Antonymy (A): Describes the relationship between lexical items that have opposite meanings. (e.g., light/heavy).

Finally, Collocation is a kind of semantic relationship among words in a given text that often co-occur. According to McCarthy and O'Dell (2005, P. 4), "[collocation] refers to the way English words are closely associated with each other." As a case in point, consider the following example in which garden collocates with digging and makes the occurrence of digging cohesive:

\section{Ali spent three hours in the garden yesterday. He was digging potatoes.}

\subsection{Review of Relevant Literature}

Lexical cohesion is a way of developing textual continuity by the use of particular lexical items. As such, lexical cohesion would be one of the significant features of the text texture achieved through lexical semantic relations dominating the arrangement of propositional units in a text. Concerned researchers and practitioners of the field have made an endeavor to compare and contrast the type and frequency of lexical cohesion devices in different languages (e.g., Dahl, 2000; Ercan \& Cicekli, 2008; Behjat, 2009; Gonzalez, 2011). As a consequence, relevant literature on the textual links, and more specifically on the lexical cohesive devices, would be classified in two parts: theoretical background and empirical background.

From the theoretical point of view, there have been a number of theories formulated based on the concept of lexical cohesion, all of which are rooted in Hasan's (1984) model of cohesion. The most salience, however, is Hoey's (1991) theory of lexical cohesion, which was further expanded in his book Lexical Priming: A New Theory of Words and Language (2005). Hoey believes that lexical patterning is an important process in the creation of both cohesion and 
coherence of a given text and must be taken into consideration. Thus, the lexical patterning process was so important for Hoey that he claimed "the study of the greater part of cohesion is the study of lexis, and the study of cohesion in text is, to a considerable degree, the study of patterns of lexis in text." (P. 10)

From the empirical point of view, notably, many studies have been conducted in the field of language teaching to make a contrastive analysis of the links of textuality or lexical cohesive signals used in various languages (e.g. Zhu, Zheng, \& Miao, 2001; Zhang \& Liu, 2003; Hyland, 2005). Few researchers, however, have made an attempt to fathom out the application of lexical cohesive markers in English and Persian texts. (e.g., Johns, 1980; Mohebbi, 1998; Veisi, 2002; Mirshekaran, 2003)

In this regard, Yarmohammadi (1995) carried out a project in which he aimed to determine the frequency and different types of lexical cohesion in English and Persian journalistic political texts as well as the density of lexical types in these texts. The source of data for his study was 50 political texts extracted from two newspapers published in Iran; namely, Kayhan international in English and Kayhan in Persian, 25 texts from each language. The first 250 words from each text were analyzed to ensure the equality of data in both languages. The findings illustrated that repetition was most frequent in both English and Persian texts, but the average percentage was higher for the Persian texts $(65.88 \%$ vs. $57.43 \%)$. Subsequently, synonymy and hyponymy were used more frequently in English texts compared to those used in Persian texts. Interestingly, it was noted that the density of the parallel English and Persian newspaper texts were almost the same.

In a similar vein, in 2011, Mirzapour and Ahmadi made a contrastive analysis between English and Persian research articles published in literature and linguistics fields to compare the frequency of lexical cohesion devices used in the related articles. Using 60 research articles, 30 from each language, they found out that the most frequent lexical cohesive markers employed in both sets of texts were repetition, collocation, and synonymy, respectively. It was also concluded that unlike Persian data that made frequent use of repetition and synonymy, the general tendency in English data was towards the use of repetition and collocation.

In translation studies, researchers have also conducted a number of experiments to find out the relationship between lexical cohesion and translation studies. As an example, Sahragard (1992) conducted a study comparing contemporary English plays with their corresponding Persian ones as well as Persian translations of English plays regarding the frequency of different sub-types of lexical cohesion used in them. He concluded that repetition, compared to other sub-types, played a major role in all sets of texts. In this regard, Veisi (2002) also carried out a contrastive analysis of lexical cohesive markers used in literary English texts and their corresponding Kurdish translations. The findings indicated that repetition was the most frequent used marker in English texts, whereas Kurdish texts were denser in this connection. It was also found out that the difference between the density of lexical cohesive markers in English and Kurdish texts was not statistically significant.

It is a commonly held belief among practitioners of the field that cohesive types vary across different genres and registers. Current findings of the related empirical studies have revealed that cohesion alters within different registers (e.g., Louwerse, McCarthy, McNamara \& Graesser, 2004), as well as different genres such as text and conversation (Taboada, 2004). In general, lexical cohesion is one of the main types of the links of textuality in various genres. However, different genres employ different types and frequencies of the lexical cohesive markers. That is, a given cohesive device or marker is used more frequently in a given genre compared with the others. As an example, the genre of legal discourse enjoys the most frequent use of lexical cohesive markers. (Yankova, 2006)

Of the most widely investigated genres in descriptive studies are narratives because they contain a rich source of participant chains, temporal, and spatial progression. In this regard, in 2003, Mirshekaran made a comparative study of lexical cohesive markers in Persian narrative and expository texts. The results indicated that the frequency of repetition was higher in expository texts compared to narrative ones. The order of frequency of sub-types occurring in these texts also revealed roughly the same pattern for the first three sub-types of repetition, synonymy, and collocation, but they differed in the last four categories- that is, hyponymy, meronymy, general nouns, and antonymy. From the educational perspective, researchers have performed a number of studies on the contrastive analysis of lexical cohesion markers due to their importance in teaching writing and reading to foreign language learners. As an example, MacMillan (2007) conducted a project in which it was found out that lexical cohesion played a basic role in reading comprehension sections of different types (paper-based, computer-based or internet-based) of TOEFL tests. The findings also revealed that all reading comprehension questions on the test involved the identification of different cases of lexical repetition.

As it has been observed from these and many other studies conducted on the comparative analysis of lexical cohesion markers, various languages make different use of such markers. A given language, however, may use some specific kinds of cohesive markers more than the others. In other words, cohesion analysis may be of great help in specifying the type and frequency of cohesive devices which specific languages enlist them differently. As such, the present study is devoted to a contrastive analysis of links of textuality in abstracts written by Persian and English writers in clinical psychology journals.

On the basis of the above, the following research questions were formulated:

1) What are the differences and similarities existing between English and Persian abstracts in psychological texts in terms of the degree and frequency of lexical cohesive sub-types?

2) What type of text is denser in terms of the lexical cohesive devices it employs? 
Accordingly, an attempt was made to specify the frequency of lexical cohesion sub-types in the abstract section of clinical psychology essays written in English and Persian. In addition, this study sought to compare the density of cohesive markers utilized in the said texts.

\section{Materials and Methods}

The target corpora for this research constitute abstracts belonging to English and Persian clinical psychology journals. Forty abstracts extracted from 40 journal articles written in English and Persian on clinical psychological issues, 20 from each language, were selected. Care was taken to ensure that the selected abstracts were similar in length and topic. Consequently, only the first 100 words from each text were analyzed. Based on the analytical framework introduced by Halliday and Hasan (1976), lexical cohesion sub-types, considered for investigation in this study, were Repetition, Synonymy/Near-Synonymy, Antonymy, Hyponymy, and Collocation. The Appendix provides a clear example for each sub-type in both Persian and English texts.

To analyze the texts, first the researchers identified the number of lexical cohesive ties for each sentence, and then, each tie was examined for identifying the related type of lexical cohesion there in. Next, the distance between the presupposed and presupposing elements was determined for each tie. Finally, various types of lexical cohesion for each text were specified and their relevant frequencies along with their percentage values were computed. A ChiSquare test was administered to determine whether the difference between the mean percentages of the sub-types in the two groups of abstracts was statistically significant.

In addition, to determine the densities of the texts under investigation, the total number of lexical ties employed in the texts was divided by the total number of sentences in the texts. This was followed by a Chi-Square test so as to find the possible existing differences between the mean percentage values of the lexical cohesion sub-types employed in writing the abstracts in the languages under investigation.

\section{Results and Discussion}

Table 1 shows the average percentages of lexical cohesion sub-types in English and Persian texts. As it is displayed in the table, repetition is the most frequently used sub-type of lexical cohesion in English texts. The next frequent lexical cohesion devices are synonymy, hyponymy, collocation, and antonymy, respectively. It is clearly observed that, like English texts, repetition is the most frequent sub-type employed in the Persian texts. However, synonymy, collocation, hyponymy, and antonymy are sub-types with lower frequencies. Interestingly, except for collocation and hyponymy sub-types, other lexical cohesion categories are almost the same in both languages.

Table1. The frequency of lexical cohesion devices in English and Persian in contrast

\begin{tabular}{lcccccc}
\hline & Repetition & Synonymy & Antonymy & Hyponymy & Collocation & Sum \\
\hline Frequency of Persian articles & 520 & 50 & 23 & 33 & 34 & 660 \\
Percentages of Persian articles & 78.8 & 7.6 & 3.5 & 5 & 5.1 & 100 \\
Frequency of English articles & 570 & 74 & 29 & 46 & 35 & 754 \\
Percentages of English articles & 75.7 & 9.8 & 3.8 & 6.1 & 4.6 & 100 \\
\hline
\end{tabular}

All in all, both English and Persian texts reveal a general tendency towards the use of repetition lexical cohesion subtype more than the others. Surprisingly, the average number of repetitions in English is considerably higher than that of Persian abstracts (570 vs. 520). In both texts, antonymy seemingly plays a minor role in producing cohesion. However, synonymy and hyponymy are used more frequently in English texts compared with the Persian ones (i.e., $74 \& 46$ vs. $50 \& 33$ respectively). Ultimately, the frequency of collocation is almost the same in both English and Persian texts (i.e., 35 vs. 34 respectively).

In order to answer the first research question, and to determine whether the difference between the mean percentages of lexical cohesion sub-types in English and Persian psychological texts is statistically significant, a Chi-square test was run. According to Table 2, the results of the Chi-Square test reveal that there is a statistically significant difference between lexical cohesion devices in both English and Persian texts only in terms of synonymy $(p<0.05)$, while for other devices such difference was not statistically meaningful ( $p>0.05)$.

Table 2. Results of Chi-square test

\begin{tabular}{lccccc}
\hline & Repetition & Synonymy & Antonymy & Hyponymy & Collocation \\
\hline Kolmogorov-Smirnov Z & .632 & 1.107 & .474 & .791 & .316 \\
Asymp. Sig. (2-tailed) & .819 & .172 & .978 & .560 & 1.000 \\
\hline Chi-Square & .388 & 3.941 & .793 & .893 & .002 \\
df & 1 & 1 & 1 & 1 & 1 \\
Asymp. Sig. (2-tailed) & .533 & .047 & .373 & .345 & .967 \\
\hline
\end{tabular}

As the figures in Table 2 indicate, in the case of synonymy, the differences are statistically significant. The results also show that repetition and synonymy are more frequently used in English psychological texts than in Persian ones. The frequency of other lexical cohesion devices is almost the same in both texts.

The second research question-that is, the densities of lexical cohesion in both texts were determined by dividing the total number of lexical ties in each language by the total number of sentences. The obtained figures are 5.4 and 3.6 for English and Persian languages, respectively. By running a two-tailed t-test, it became clear that the difference was 
statistically significant. Evidently, the English psychological texts were denser compared to their corresponding Persian abstracts.

Yarmohammadi (1995) also conducted a similar study in which the aim was to determine the frequency of different types of lexical cohesion in English and Persian journalistic political texts. Comparing the current study with that of Yarmohammadi, it seems that both English and Persian languages exhibit a general tendency towards the use of repetition. In journalistic texts, however, Persian texts were characteristically different because they used a higher density in terms of repetition unlike English journalistic texts. On the contrary, English psychological texts possessed a higher degree of density for the repetition lexical cohesion devices. In Persian journalistic texts, on the other hand, hyponymy was more frequent than its corresponding occurrence in English texts. In English texts, the order of lexical cohesion devices was Repetition, Synonymy, Meronymy, Collocation, Hyponymy, General nouns, and Antonymy, while in Persian texts it was Repetition, Meronymy, Synonymy, Collocation, General nouns, Hyponymy, and Antonymy with decreasing percentages of occurrence, respectively. As a whole, the analysis of data in the psychological texts revealed that all lexical cohesion devices in English texts had a higher frequency than Persian texts. It was further indicated that, in the cases of repetition and hyponymy, the differences were statistically significant in journalistic texts, whereas in psychological texts the differences were significant just for the synonymy sub-type. Overall, it can be inferred that the type of the text may have a determinant influence on the type and frequency of lexical cohesion devices.

\section{Conclusion}

This paper was a contrastive study of lexical cohesion markers employed in English and Persian psychological abstracts. In this study, only five lexical cohesion devices were taken into consideration, i.e., Repetition (R), Synonymy (S), Antonymy (A), Hyponymy (H), and Collocation (C). The general findings drawn from this study were as follow: In English texts, the order of frequency in lexical cohesion devices was R, S, H, C, A, whereas in Persian texts it was R, S, C, H, A with descending percentages of occurrence, respectively. Both texts exhibited a general tendency towards the use of repetition more than the other devices; however, English texts were denser in this respect. Based on Chi-Square test, between lexical cohesion devices in both English and Persian texts, there was a statistically significant difference only in synonymy items, while among other devices no meaningful difference was perceived. In the final analysis, it can be particularized that repetition and synonymy were more frequent in English psychological texts than Persian ones, but the frequency of other lexical cohesion devices was almost the same for both text groups.

4.1 Pedagogical implications

The present study was an attempt to analyze comparatively the links of textuality in abstracts written by Persian and English writers in clinical psychology journals. The findings revealed that the university students majoring in the psychology field indicated a greater tendency towards the use of repetition, as a lexical cohesive sub-type, in writing abstracts. This means that they have insufficient vocabulary knowledge, which is an important aspect of fluency in writing. As a consequence, the novice writers need to be aware of this requirement in order for them to be able to write an effective abstract. Accordingly, teachers might make the best use of the present study's findings so as to teach students to use more morphologically complex words; i.e., complex repetitions instead of simple words. To do so, they should develop writing activities that are in line with learning lexical cohesion devices such as synonymy, hyponymy, antonymy, and the like.

The results of this study may also have some implications for improving proficiency in the reading comprehension of students because if learners become aware of the textual specifications of different genres or different written texts utilizing different links of textuality, and more specifically different lexical cohesive devices, they may be able to interact with and comprehend the text with less difficulty.

\section{References}

Behjat, F. (2009). Cohesive devices in English novels and their corresponding Persian translations. Journal of Teaching English as a Foreign Language and Literature, 1 (3), 107-118.

Dahl, T. (2000). Text summarization: From human activity to computer program. The problem of tacit knowledge. Hermes, Journal of Linguistics, 25, 113-131

De Beaugrande, R., \& Dressler, W. U. (2004). Introduction to Text Linguistics. London: Longman Education Press. Ercan, G., \& Cicekli, I. (2008). Lexical cohesion based topic modeling for summarization. Proceedings of the Cicling, 2008, 582-592.

Fairclough, N. (1995). Critical Discourse Analysis. Boston: Addison Wesley.

Gonzalez, M. (2011). Lexical cohesion in multiparty conversations. Language Sciences, 33 (1), 167-179

Gutwinski, W. (2007). Cohesion in Literary Texts. The Hague: Mouton.

Halliday, M. A. K. (1985). An Introduction to Functional Grammar (2 ${ }^{\text {nd }}$ Ed.). London: Edward Arnold.

Halliday, M. A. K., \& Hasan, R. (1976). Cohesion in English. London: Longman.

Hasan, R. (1984). Coherence and cohesive harmony. In J. Flood (Eds.), Understanding Reading Comprehension: Cognition, Language, and the Structure of Prose (pp. 181-219). Newark: International Reading Association.

Hoey, M. (1991). Patterns of Lexis in Text. Oxford: Oxford University Press.

Hoey, M. (2005). Lexical Priming: A New Theory of Words and Language. London: Routledge.

Hyland, K. (2005). Metadiscourse: Exploring Interaction in Writing. London: Continuum.

Johns, A. M. (1980). Cohesion in written business discourse: Some contrasts. The ESP Journal, 1(1), 35-44. 
Louwerse, M. M., McCarthy, Ph. M., McNamara, D.S., \& Graesser, A.C. (2004). Variation in language and cohesion across written and spoken registers. In K. Forbus, D. Gentner, \& T. Regier (Eds.), Proceedings of the 26th Annual Meeting of the Cognitive Science Society ( pp. 843-848), Mahwah, NJ: Erlbaum.

MacMillan, F. (2007). The role of lexical cohesion in the assessment of EFL reading proficiency. Arizona Working Papers in SLA and Teaching, 14, 75-93.

McCarthy, M., \& O’Dell, F. (2005). English Collocations in Use. Cambridge: Cambridge University Press.

Mirshekaran, I. (2003). Lexical cohesion in Persian narrative and expository text types. Unpublished master's thesis, Shiraz University, Iran.

Mirzapour, F., \& Ahmadi, M. (2011). Study on lexical cohesion in English and Persian research articles: A comparative study. English Language Teaching, 4 (4), 245-253, doi:10.5539/elt.v4n4p245

Mohebbi, B. (1998). A contrastive analysis of ellipsis in English texts and their translation equivalents in Persian. Unpublished master's thesis, Shiraz University, Iran.

Sahragard, R. (1992). Lexical cohesion in English and Persian. Paper presented at Tabriz- Baku $1^{\text {st }}$ Conference on Language Teaching Issues, Tabriz. Iran

Taboada, M. T. (2000). Collaboration through talk: the interactive construction of task oriented dialogue in English and Spanish. Unpublished doctoral thesis. University of Madrid, Spain.

Tanskanen, S.-K. (2006). Collaborating Towards Coherence: Lexical Cohesion in English Discourse. Amsterdam: Benjamin.

Van Dijk, T. (1977). Coherence, Text and Context: Exploration in the Semantics and Pragmatics of Discourse. London: Longman.

Veisi, A. (2002). Lexical cohesion in English and Kurdish in contrast. Unpublished master's thesis, Shiraz University, Iran.

Yankova, D. (2006). Semantic relations in statutory texts: A study of English and Bulgarian. SKY Journal of Linguistics, 19, 189-222.

Yarmohammadi, L. (1995). Fifteen Articles in Contrastive Linguistics and the Structure of Persian: Grammar, Text, and Discourse. Tehran: Rahnama Publications.

Zhang, D. L., \& Liu, R. S. (2003). Yupian lianguan yu xianjie lilun de fazhan ji yingyong (The development of the theory of text coherence and cohesion and its application). Shanghai: Shanghai Foreign Language Education Press.

Zhu, Y. S., Zheng, L. X., \& Miao, X. W. (2001). Yinghan yupian xianjie shouduan duibi yanjiu (A contrastive study of cohesion in English and Chinese). Shanghai: Shanghai Foreign Language Education Press.

\section{Appendix}

An example from each sub-type of lexical cohesive devices in both English and Persian psychology texts.

\section{Repetition (R)}

English text

Example. This review describes the role of chronic stress in the development of obesity and available methodologies for the assessment of chronic stress in humans.

Mesâl. hadaf-e in pazuheš barrasi-e $\begin{gathered}\text { Persian text } \\ \text { nešanegane extelâl-e }\end{gathered}$

Example. purpose this article investigating signs disorder

est-e-rese pas az sânehe va hambu?di afsordegi-e ezterâbe xašm va

stress after from disaster and similarity depression anxiety anger and

tajzi?eh ba extelal-e est-e-res pas az sânehe barasâs-e tafavot-e

analysis with disorder stress after from disaster based on difference

jensi-ati bud.

sex was.

\section{Synonymy (S) or Near-Synonymy}

English text

Example. The gastro-intestinal tract is well known for its largest neural network outside the central nervous system and for the most extensive immune system in the body.

\section{Persian text}

Mesâl. in motâle-eh az noē motâleat-e elmi-moqâyese?I ast. Jâme-eye

Example. this study from type studies scientific-contrastive is. Population âmâri-e pasuheše hazer šâmel-e kolipye bimârân-e mobtala be extelâl-e govareši ast statistical research present include all patients infected to disorder digestive is 
3. Antonymy (A)

English text

Example. Normal gut physiology is molded by interaction between the intestinal microbiota and the host's gastrointestinal tissues. Early studies in axenic mice demonstrated gross morphological abnormalities.

Persian text

Mesâl. jâme?ye dovvom šâmel-e koli?ye afrâd-e $\underline{\text { sâlem }}$ šâqel va hamrâhan-e Example. society second include all people healthy employed and fellows of sâleme bimârân-e govareši morâje?eh konandeh be hamân bimârestân mibâšand healthy patient digestive referred to the same hospital are.

\section{Hyponymy (H)}

\section{English text}

Example. The possible effects of enteric nerves, especially of the nonadrenergic and noncholinergic nerves, on the intestinal immune system are described.

\section{Persian text}

Mesâl. dar yek paзuheš-e modâxele?i-nim-e-âzmâyeši 120 nafar az mâdarân-e

Example. in one study interference-quasi experimental 120 people of mothers šâqel barrasi šodand. Gerdâvari-e etelâpt be komake porseš-nâmeh anjâm šod. employed investigated were. Collecting data with help of questionnaire done was.

\section{Collocation (C)}

\section{English text}

Example. A logical regression analysis was performed to test a model for the possible predictors of the two different patterns of outcome.

\section{Persian text}

Mesâl. t fehel bimâr-e mobtala be bimâri-eh qalb ke barâye avvalin-bâr taht-e jarrâhi-eh Example. Forty patients infected by illness heart who for first time under surgery bâz-e or Puq qarâr gerefteh budand entexab šodand. open vessels taken have been selected were. 